\title{
Você é Sertão? - \\ Marcel Mauss, a Ciência Política e o Sertão de Guimarães Rosa
}

\author{
¿Usted es Sertão? -
}

Marcel Mauss, la Ciencia Política y el Sertão de Guimarães Rosa

Are you Sertão? -
Marcel Mauss, the Political Science and the Sertão of Guimarães Rosa

Flávia Lages de Castro

Palavras chave:

O presente artigo tem por objetivo discutir as visões do personagemlugar "Sertão", apresentado na obra de João Guimarães Rosa: Grande

Guimarães Rosa Sertão: Veredas. Através das possibilidades interpretativas, debatem-se as modalidades simbólicas do Sertão tendo por base a teoria de Marcel

Mauss Mauss, buscando perceber de que forma o raciocínio pautado neste

Mana

Ciência Política autor, aplicado ao Sertão - criado e apresentado por Guimarães Rosa -, pode ser utilizado para uma percepção de uma análise política. Restam claras as múltiplas possibilidades interpretativas do personagem-lugar

Simbolismo assim como a sua utilidade na reflexão histórico-social da política a partir das ideias e definições de Mana que Mauss criou. 


\section{Resumen:}

El presente artículo tiene por objetivo discutir las visiones acerca del personaje-lugar "Sertão" (Sertón), presentado en la obra de João Guimarães Rosa: Grande Sertão: Veredas (Gran Sertón: Veredas). A través de las posibilidades interpretativas, se debaten las modalidades simbólicas del Sertão, tomando como base la teoría de Marcel Mauss, buscando percibir de qué forma el raciocinio con base en este autor, aplicado al Sertão - creado y presentado por Guimarães Rosa -, puede ser utilizado para una percepción de un análisis político. Restan evidentes las múltiples posibilidades interpretativas del personaje-lugar como también su utilidad en la reflexión histórico-social de la política a partir de las ideas y definiciones de Mana las que Mauss ha creado.

\section{Palabras clave:}

Guimarães Rosa

Mauss

Mana

Ciencia Política

Simbolismo
Keywords:

Guimarães Rosa

Mauss

Mana

Political Science

Symbolism

\section{Abstract:}

The aim of the present paper is to discuss the views on the character-place "Sertão", presented in the work of João Guimarães Rosa: Grande Sertão: Veredas (The Devil to Pay in the Backlands). Through the interpretive possibilities, the symbolic modalities of Sertão are debated based on Marcel Mauss's theory, seeking to understand how the thinking process founded on this author, applied to Sertão - created and presented by Guimarães Rosa -, can be used for perceiving a political analysis. The multiple interpretative possibilities of the character-place remain clear, as well as its utility in the social historical reflection of politics from the ideas and definitions of Mana, which were created by Mauss. 


\section{Você é Sertão? - Marcel Mauss, a Ciência Política e o Sertão de Guimarães Rosa}

\section{1 - INTRODUÇÃO}

"Você é o Sertão?" Perguntou Riobaldo a um vulto no fim de uma peleja ${ }^{2}$. Personificado, eivado de poder e gana de querer, o Sertão de Rosa é algo mais que um lugar, algo menos que um espaço físico, algo entre amigo, patrão e vilão e, por isso, muitos estudos buscam aproximar teorias à criação magistral de Guimarães Rosa em "O Grande Sertão: veredas" ou, sentido oposto, tomam o "Grande Sertão" e conduzem-no na direção de teorias das mais variadas origens.

Por fato pode-se apontar a criatividade de Guimarães Rosa em cultivar possibilidades capazes de causar de estranhezas positivas à teorias das mais rebuscadas. Neste sentido, outro escrito do autor, o conto "A terceira margem do rio"3, é paradigmático, visto que, a tridimensionalidade da disposição dos personagens, emoções, possibilidades, enredo, demonstram a amplitude da criatividade de Rosa.

Este artigo, de pequena pretensão, tem por objetivo traçar linhas reflexivas sobre a relação das ideias de Mauss, o Sertão de Rosa - principal lugar/personagem do livro e a ciência política emaranhada nas ideias de poder dos personagens e do tempo histórico que o romance alinhava representações.

\section{2 - O SERTÃO POR RIOBALDO}

O personagem-narrador da estória de Rosa dá o tom dos poderes postos do personagem-lugar, o Sertão. De pronto, percebe-se que, a reflexão da questão política através de "Grande Ser- tão: veredas" perpassa a noção de poder regional e transcende do poder local para o poder "do" local.

Assim sendo, tem-se Riobaldo afirmando que sequer Deus é capaz de - sem armas - ser mais forte que o Sertão: "O senhor sabe: sertão é onde manda quem é forte, com as astúcias. Deus mesmo, quando vier, que venha armado!"4

Ao mesmo tempo, mesmo "o mais forte" é inferior ao próprio Sertão, mais que um lugar, menos que um ser sobrenatural, pois revestido de poder em si e com disputas de poder dentro de si, ainda assim não pode ser domado porque:

Rebulir com o sertão, como dono? Mas o sertão era para, aos poucos e poucos, se ir obedecendo a ele; não era para à força se compor. Todos que mal montam no sertão só alcançam de reger em rédea por uns trechos; que sorrateiro o sertão vai virando tigre debaixo da sela.

Para Riobaldo, é algo a ser domado, senão na realidade, ao menos em pensamento, como forma de sobrevivência: "(...) sertão é onde o pensamento da gente se forma mais forte que o poder do lugar."

Isto porque, o Sertão de Riobaldo, tem por característica a violência: "Sertão é o penal, o criminal. Sertão é onde o homem tem de ter a dura nuca e mão quadrada." Porque sinônimo - em algumas passagens do livro - de jagunço e este, como braço armado do poder local, é apresentado romanticamente até por estar em vias de extinção ${ }^{7}$, antônimo de urbanidade porque: "(...) cidade acaba com o sertão. Acaba?"8

\section{3 - MANA, MAUSS E O SERTÃO}

Segundo Lévi-Strauss, para Mauss todos os fenômenos sociais podem ser 
assimilados à linguagem, assim, expressões como Mana tem função semântica, "cujo papel é permitir ao pensamento simbólico exercer-se apesar da contradição que lhe é própria." ${ }^{9}$

O mana, portanto, nos é dado como algo não apenas misterioso, mas também separado. Em resumo, o mana é primeiramente uma ação e um certo gênero, isto é, a ação espiritual à distância que se produz entre seres simpáticos. É igualmente uma espécie de éter, imponderável, comunicável, e que se espalha por si mesmo. Além disso, o mana é um meio, ou, mais exatamente, funciona num meio que é mana. É uma espécie de mundo interno e especial, onde tudo se passa como se ali somente o mana estivesse em jogo. É o mana do mágico que age pelo mana do rito sobre o mana do indalo, o que põe em ação outros manas, e assim por diante..$^{10}$

Desta forma, entender o Sertão de Rosa como Mana é vê-lo como a maneira pela qual o autor conseguiu expressar semanticamente um conjunto múltiplo - portanto não elencável em uma solitária categoria explicativa/narrativa - que abrange do sentido físico ao psíquico, passando pelo poder, pelo amor e tantas outras pequenas nuances possíveis que Rosa colocou na boca do personagem-narrador Riobaldo. ${ }^{11}$

Por outro lado a questão da Magia e sua relação com o Sertão em O Grande Sertão: Veredas é explícito já que, segundo Maria Luiza de Arruda o pacto com o diabo é a "obsessão central" do narrador Riobaldo bem como variadas possibilidades religiosas vistas de forma ímpar ou emaranhadas no discurso do ex- jagunço.
A existência desse compromisso,
e, principalmente, a dúvida quanto
à sua validade, angustia o herói, a

tal ponto que ele procura de todas as maneiras chegar a uma verdade. (...) Sem a certeza do compromisso assumido, sem comprovação do fato de "ter diabo", Riobaldo apega-se a todas as religiões (...).

A possibilidade do mágico e do irracional alinhavam a trama contada pelo narrador dando-lhe forma, ao mesmo tempo que demonstram a intimidade de Riobaldo com o que conta e o motivo pelo qual o faz. Isto é feito pelo autor quando coloca sob sua narrativa mais que indicações realistas do ser e viver de um lugar determinado.

Neste sentido o Sertão, personagem-mana, pode ser entendido de várias maneiras: de maneira mais óbvia como mana em si, conforme propõe Sylvia Schiavo $^{13}$, ou como símbolo do inconsciente tendo por par a vereda, a consciência. ${ }^{14}$

Esta última interpretação parece ter tido - pelo menos por algum tempo a aquiescência de Guimarães Rosa haja vista a afirmação de Ronái:

O sertão acaba sendo caos ilimitado de que só uma parte ínfima nos é dado conhecer, precisamente a que se avista ao longo das veredas, tênues canais de penetração e comunicação. Assim, o sinal -:- entre os dois elementos do título teria valor adversativo, estabelecendo a oposição entre a imensa realidade inabrangível e suas mínimas parcelas acessíveis. [...] E também, segundo me confirmou certa vez o próprio Autor, entre o inconsciente e o consciente. ${ }^{15}$

Martins vai além, extrapolando o simbólico percebe arquétipos alquímicos:

(...) o Sertão é o terreno da eternidade e da solidão, onde se fala a língua metafísica, onde o homem é o eu que não 
encontrou ainda o tu; por isso são os anjos ou os diabos que manuseiam a língua. As forças arquetípicas preponderam descontaminadas.

A guisa de análise e exercício intelectual, ao ler-se a obra de Rosa como um todo e, Grande Sertão: veredas especificamente, o lugar, ou melhor, os lugares trabalhados por ele, vistos de maneira simplista ou como mana ou como símbolos de consciente e inconsciente, não dão conta das múltiplas e ímpares possibilidades plurais que o "personagem" Sertão apresenta enveredando-se nos personagens humanos tanto quanto estes nele. Assim, se deve pensar de ângulos múltiplos as numerosas arestas que este é apresentado.

A arquitextualidade ${ }^{17}$ - uma das possibilidades de buscar visualizar mais que duas dimensões da questão rosiana, leva a uma necessidade - indicada de maneira geral por Philippe Willemar - de haver separação entre escritor e autor: o primeiro sendo a entidade pessoal, física e psíquica e o segundo o escritor transmudado quando "manipulando sabiamente a língua, pratica uma espécie de feitiçaria". ${ }^{18}$

O autor Guimarães Rosa é então - e indiscutivelmente - um "mestre feiticeiro" porque busca não somente usar a língua como parte de um todo que pretende construir mas, principalmente, constrói cada palavra, como quem erige tijolo por tijolo e pedra por pedra para depois alocá-los em um edifício. Neste sentido Rónai afirma: "fez, em suma, Guimarães Rosa, em relação à linguagem, o que todos os ficcionistas fazem da realidade, sua matéria prima: desagregam-na e reconstituem-na a seu bel prazer (...)". ${ }^{19}$

Somando à arquitextualidade a intertextualidade ${ }^{20}$, (se tratar-se de realização magistral) um escrito torna-se atemporal, na medida que consegue tra- tar de algo que mantêm distância segura de algozes moralistas e de guardiões raivosos do status quo, enquanto desfila sem pudores as mazelas que deseja discutir sem censura.

Isto não é exclusivo dos tempos modernos. Assim o fez Plauto ${ }^{21}$ na Roma Antiga, com meios, nomes e locais gregos para abordar assuntos incomodamente romanos e contemporâneos aos seus que, de outra maneira, não seriam aceitos sequer pela audiência. Assim se mostra Rosa que, separando autor e escritor, fala de jagunços que nunca foi e de um amor estranho à luz do dia. Como um feiticeiro mostram, esses artífices da arquitextualidade e da intertextualidade, sem mostrar e fazem surgir à vista de todos algo que não cabia antes.

\section{4 - CONCLUSÃO}

A contribuição de Mauss, visto através das lentes de Guimarães Rosa em Grande Sertão: veredas, para a ciência política é a possibilidade de se compreender o poder sem a existência do mesmo, tanto como um vácuo coberto pela crença religiosa ou mágica, quanto pelo uso do mágico - mana - como forma de alcançar o poder.

É este o caminho escolhido e triIhado pelo personagem Riobaldo, o uso do mana para obter poder: para vencer o mal ele associa-se ao mal e entrega o belo em sua vida, o objeto de seu amor, em contrapartida.

Sob este ponto de vista, o coronel, o poder local, é visto por Rosa como um devedor do Sertão, este sim senhor de tudo e todos que estão nele. Percebe-se então que, em se considerando esta interpretação como provável, os regionalismos e os poderes regionais, tomados como categoria, merecem ser percebidos 
além dos indivíduos porque, das forças políticas atuantes, segundo esta possível interpretação de Rosa, é inescapável a inserção do lugar como força primordial, ainda que mítica.

Não obstante, muitas são as possibilidades de interpretação de textos magistrais como este - e outros - de Guimarães Rosa que, até por não poderem ser definitivas, servem para reflexões interessantes.

Mesmo porque, permitindo-nos um exercício de imaginação... Se - possível e provável - o senhor João apenas seguiu instintos objetivando realizar de forma palpável seu inegável talento, resta-nos ainda algo positivo, a possibilidade sorrir das centenas (milhares?) de intelectuais (de nós mesmos?) que passaram, passam e passarão a vida a se amofinar com intenções e objetivos que o cérebro rosa de Guimarães não chegou a perceber, pois seu dom e coração bombearam rápido demais sua criatividade para o papel.

\section{Bibliografia:}

BARRETO, Rócio S. N. Magia, mana: aspectos centrais a partir das obras de Durkheim e Mauss. Disponível em <http://www.artigosbrasil.net/art/ mundo/7889/magia-mana.html>. Acesso em 01 de maio de 2011.

BERRINI, Beatriz (org.). Convivendo com Guimarães Rosa: Grande Sertão: veredas. São Paulo: EDUC, 2004.

CARVALHO, José Murilo de. Mandonismo, Coronelismo, Clientelismo: Uma Discussão Conceitual. Dados [online]. 1997, vol.40, n.2. Disponível em: $<$ http://www.scielo.br/scielo.php?script=sci_ arttext\&pid=S0011-52581997000200003\&lng=e n\&nrm=iso>. Acesso em 30 mar 2012.
CERIBELLI, Marilda. Teatro Romano e as comédias de Plauto. Rio de Janeiro: Sete Letras, 1995.

LEONEL, Maria Célia. Guimarães Rosa: magma e gênese da obra. São Paulo: UNESP, 2000.

LIPPOLIS, Enrico. Grande Sertão: veredas: o sertão como símbolo do inconsciente. Lorena, Revista Ângulo, n. 115, out-dez 2008, pp. 73-81.

MARTINS, José Maria. Guimarães Rosa: o alquimista do coração. Petrópolis, RJ: Vozes, 1994.

MAUSS, Marcel. Sociologia e antropologia. São Paulo: Cosac Naify, 2003.

ROSA, Guimarães. Grande Sertão: veredas. Rio de Janeiro: Nova Fronteira, 2006.

ROSA, João Guimarães. Primeiras estórias. Rio de Janeiro: Nova Fronteira, 2005.

SCHIAVO, Sylvia. Sertão uno e múltiplo ou "lua pálida no firmamento da razão". Goiania, Sociedade e Cultura, Universidade Federal de Goiás, a. 10, n 001, pp. 41-44.

\footnotetext{
${ }^{1}$ Mestre em História Social. Professora do Curso de Produção Cultural - UFF - Niterói.

${ }^{2}$ ROSA, João Guimarães. Grande Sertão: veredas. Rio de Janeiro: Nova Fronteira, 2006, p. 591.

${ }^{3}$ ROSA, João Guimarães. Primeiras estórias. 1.ed. especial. Rio de Janeiro: Nova Fronteira, 2006

${ }^{4}$ ROSA, Grande Sertão... op. cit. ,p.19.

${ }^{5}$ Ibidem, p. 25. (grifo nosso).

${ }^{6}$ Ibidem, p. 110.

${ }^{7}$ Para José Murilo de Carvalho pode-se localizar o fim do coronelismo: “(...) o coronelismo é, então, um sistema político nacional, baseado em barganhas entre o governo e os coronéis. O governo estadual garante, para baixo, o poder do coronel sobre seus dependentes e seus rivais, sobretudo cedendo-lhe o controle dos cargos públicos, desde o delegado de polícia até a professora primária. O coronel hipoteca seu apoio ao governo, sobretudo na
} 
forma de votos. Para cima, os governadores dão seu apoio ao presidente da República em troca do reconhecimento deste de seu domínio no estado. O coronelismo é fase de processo mais longo de relacionamento entre os fazendeiros e o governo. O coronelismo não existiu antes dessa fase e não existe depois dela. Ele morreu simbolicamente quando se deu a prisão dos grandes coronéis baianos, em 1930. Foi definitivamente enterrado em 1937, em seguida à implantação do Estado Novo e à derrubada de Flores da Cunha, o último dos grandes caudilhos gaúchos." CARVALHO, José Murilo de. Mandonismo, Coronelismo, Clientelismo: Uma Discussão Conceitual. Dados [online]. 1997, vol.40, n.2. Disponível em: <http://www.scielo.br/scielo.php?script=sci arttext\&pid=S0011-52581997000200003\&lng=en\&nrm=i so>. Acesso em 30 mar 2012.

${ }^{8}$ ROSA, Grande Sertão..., op. cit. , p. 167.

9 LÉVI-STRAUSS, Claude. Introdução à obra de Marcel Mauss. IN: MAUSS, Marcel, op.cit., p. 23

10 MAUSS, Marcel. Sociologia e antropologia. São Paulo: Cosac Naify, 2003, p. 74.

11 Poderíamos ter apontado Riobaldo como personagem-narrador-protagonista, mas a narrativa de Rosa nos leva a crer que o protagonista é o Sertão em todas as possibilidades de significado e interação com os outros personagens que o autor achou por bem expor em sua obra.

${ }^{12}$ ARRUDA, Maria Luiza. O medo e o sertão: a travessia da vida e o encontro com o desconhecido. IN: BERRINI,
Beatriz (org.). Convivendo com Guimarães Rosa: Grande Sertão: veredas. São Paulo: EDUC, 2004, p. 19s.

${ }^{13}$ SCHIAVO, Sylvia. Sertão uno e múltiplo ou "lua pálida no firmamento da razão". Goiania, Sociedade e Cultura, Universidade Federal de Goiás, a. 10, n 001, pp. 41-44.

14 LIPPOLIS, Enrico. Grande Sertão: veredas: o sertão como símbolo do inconsciente. Lorena, Revista Ângulo, n. 115 , out-dez 2008, pp. 73-81.

${ }^{15}$ RONÁl apud LIPPOLIS, op. cit., p. 74.

${ }^{16}$ MARTINS, José Maria. Guimarães Rosa: o alquimista do coração. Petrópolis, Vozes, 1994, p. 57.

17 Relação "muda" que articula uma menção paratextual de pertencimento taxionômico.

18 WILLEMAR apud LEONEL, Maria Célia. Guimarães Rosa: magma e gênese da obra. São Paulo: UNESP, 2000, p. 68.

19 RÓNAI, Paulo. Vastos espaços [ensaio]; IN: ROSA, João Guimarães. Primeiras estórias. Rio de janeiro: Nova Fronteira, 2005, p. 32.

${ }^{20}$ No sentido estrito designa a transposição de um (ou vários) sistema(s) de signos noutro e desta forma colocamo-lo aqui neste texto (em contraposição ao uso "senso comum" que indica somente como crítica de fontes).

21 Tese central de Marilda Ceribelli em "Teatro Romano e as Comédias de Plauto" de 1995.

\section{Contato:}

Flávia Lages de Castro

- flavialages@id.uff.br

\section{Artigo recebido em março de 2012}

Artigo aprovado em julho de 2012 